\section{Journal of Home \\ Economics}

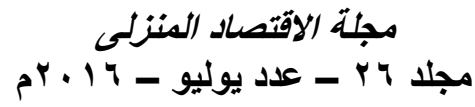

http://homeEcon.menofia.edu.eg

ISSN 1110-2578

\title{
دراسة تأثير الانواع المختلفة لأقمشة الجبردين على بعض الخواص الميكانيكية لوصلات الحياكة
}

\author{
إيناس السيد الدريدي
}

أستاذ مساعد الملابس و النسيج بقسم الاقتصاد المنزلي- كلية التربية النوعية ـ جامعة بنها

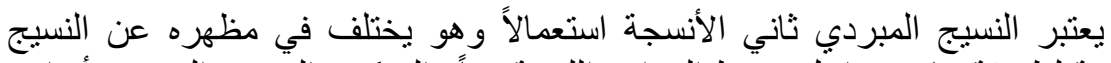

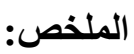

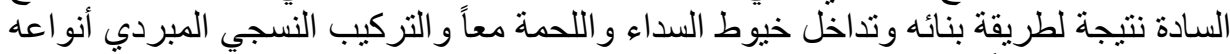

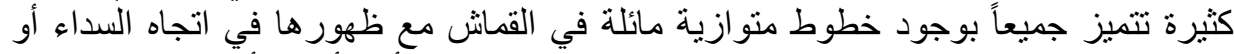

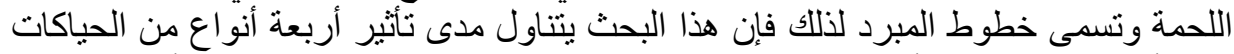

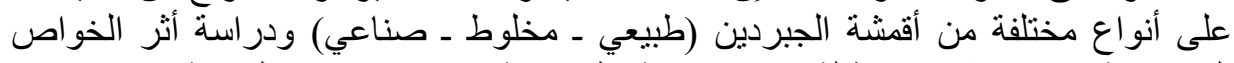

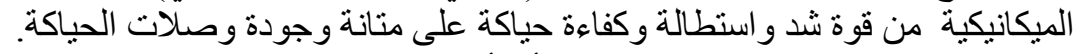

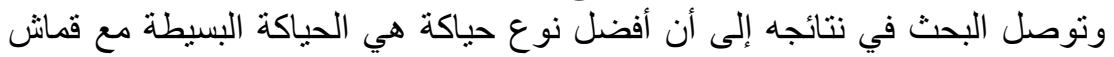

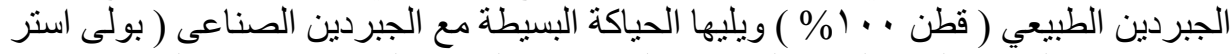

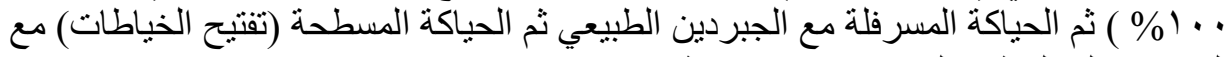

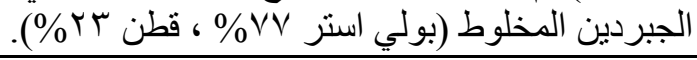

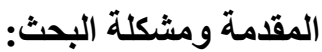

تعتبر الأقمشة أساس صناعة الملابس فهي المادة الأولية لها وهي تختلف فيما بينها

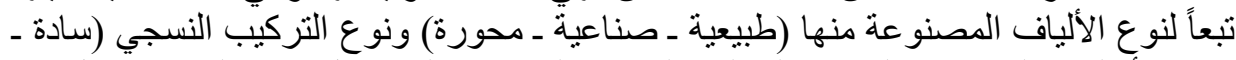

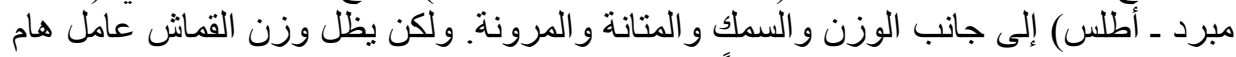

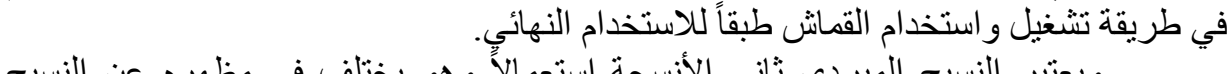

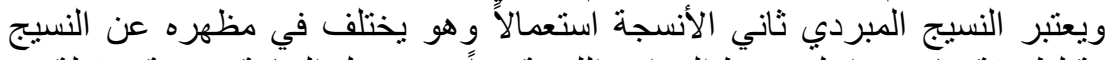

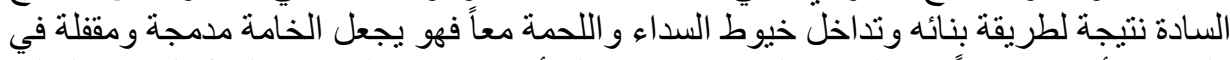

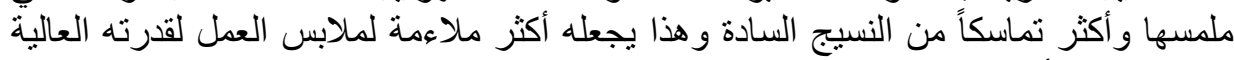

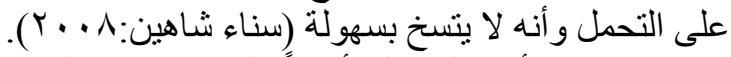

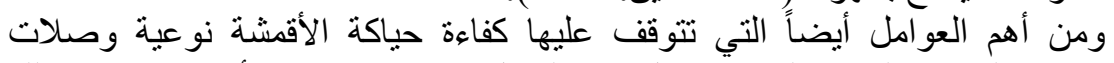

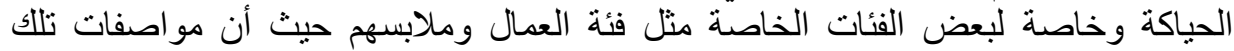

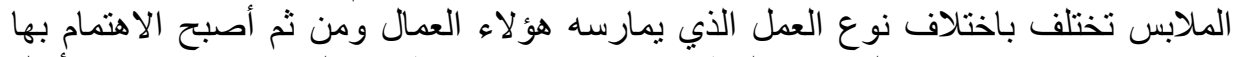

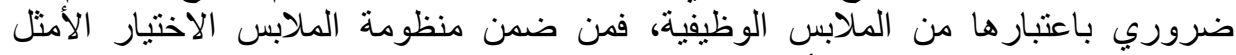
للحياكات حيث يعبر عن كفاءة الأداء الوظيفي للزي. 


\section{مجلة الاقتصاد المنزلى- مجلد بr - العدد (r) - 19 ـ r م}

ومن هنا تكمن مشكلة البحث حيث أنه من الضروري أن يحدث نر ابط بين الخامة البها

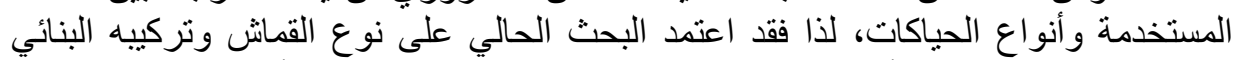

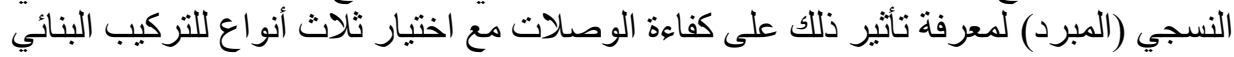

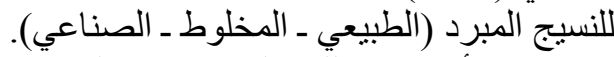

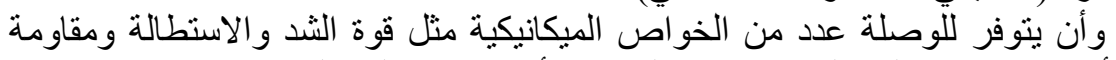

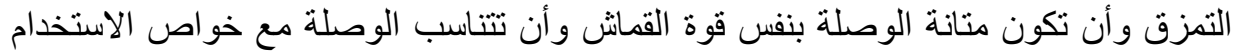

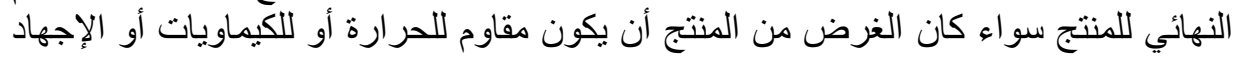

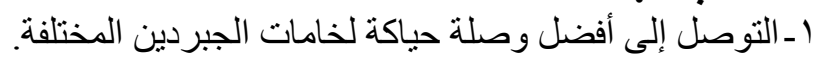

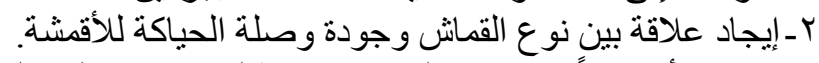

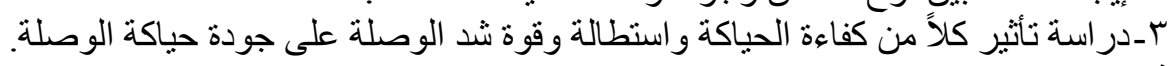

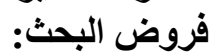
ا-نوجد فروق ذات دلالة احصائية بين اقمشة الجبردين (طبيعى - صناعى - مخلوط ) وقوة

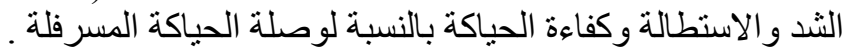

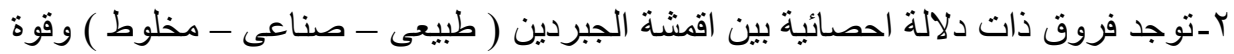

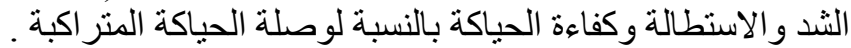

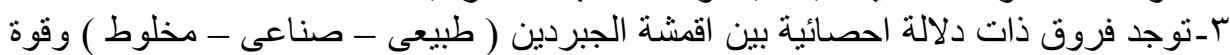

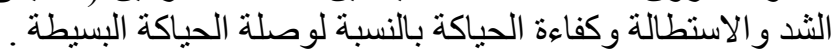

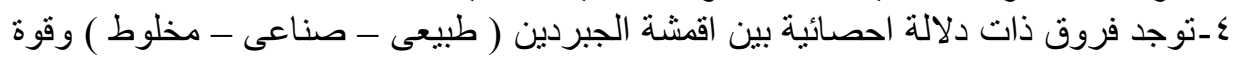

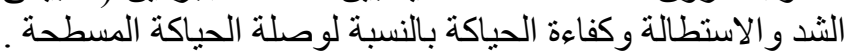

اقتصرت الدراسة على استخدام ثلاثة أنواع من أقشة الجبردين (طبيعي قطن حدود البحث:

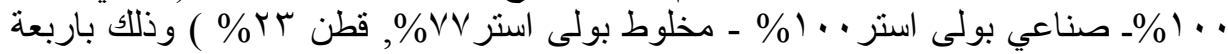

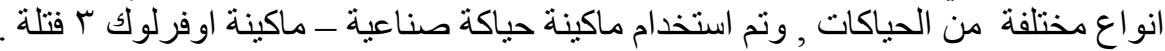
وتبع ذلك إجر اء مجموعة من الاختبار ات المعملية عليها ( قوة شد الوصلة ـ استطالة الونة

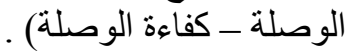
يتبع هذا البحث المنهج التجريبي و المنهج التحليلي.

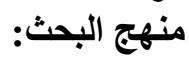
أدوات البحث:

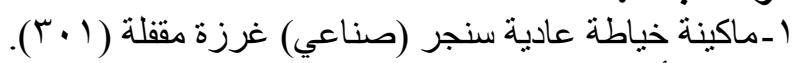

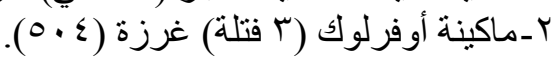

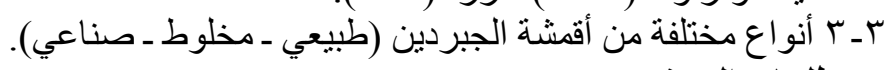

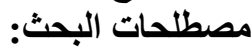
الحياكة: Sewing هي عملية شبك أطراف القماش بعضها ببعض باستعمال الإبرة و الخيط باستخدام

الماكينة. (المعجم الوجيز: 1999 (1) 


$$
\text { مجلة الاقتصاد المنزلى- مجلد بr - العدد (r) - } 17 \text { • بrم }
$$

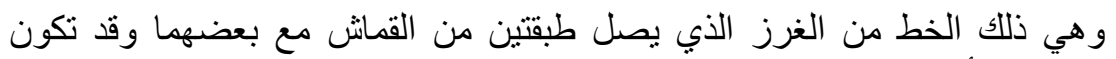

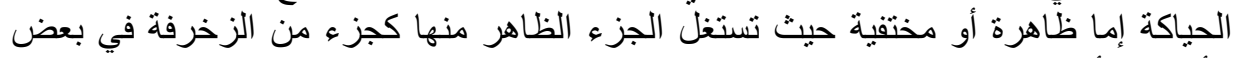

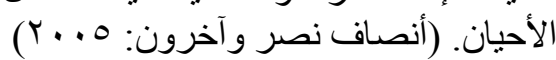

وصلات الحياكة : Sewing Joints

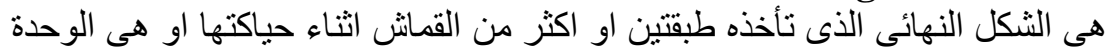

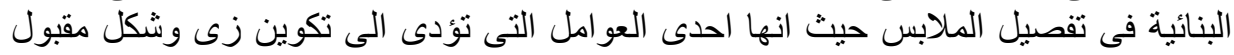

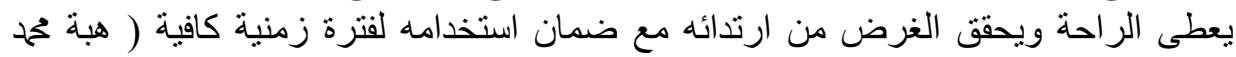

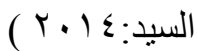

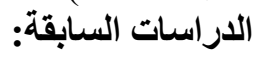

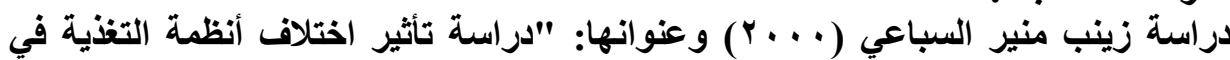

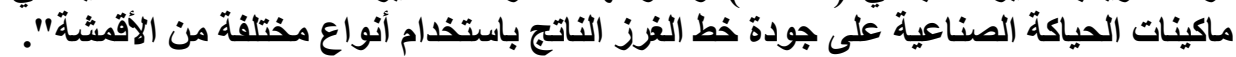

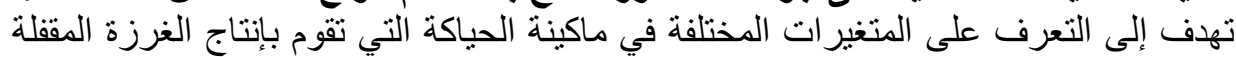

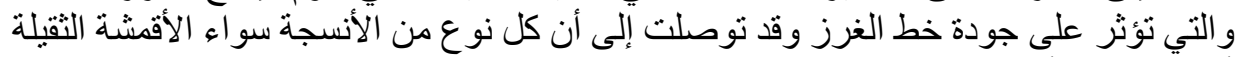

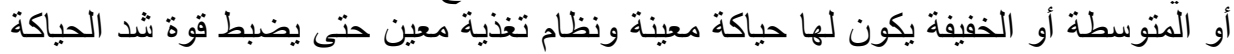

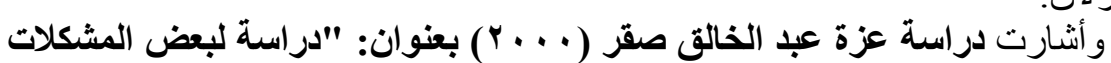

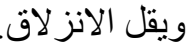

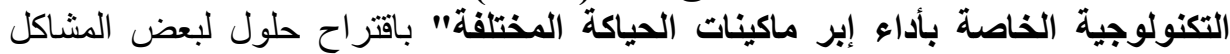

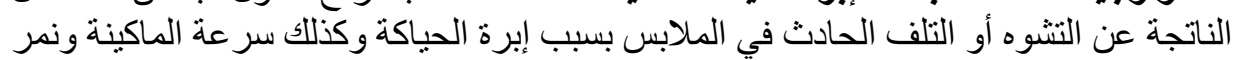

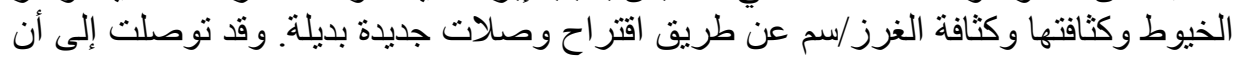

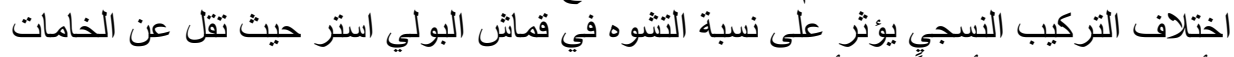

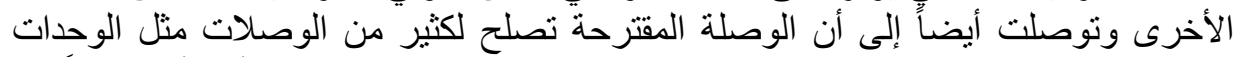

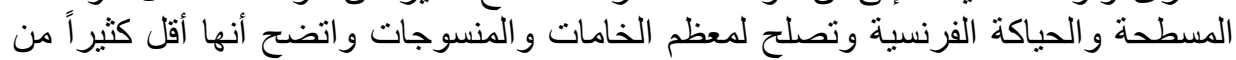

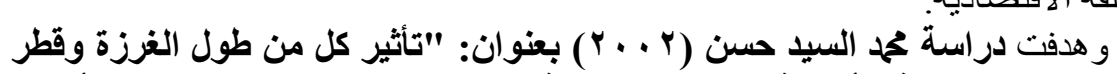
حيث التكلفة الاقتصادية.

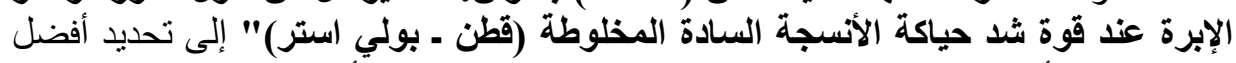

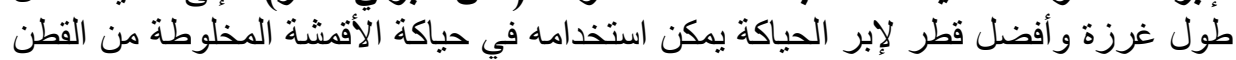

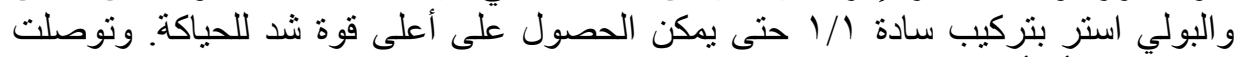

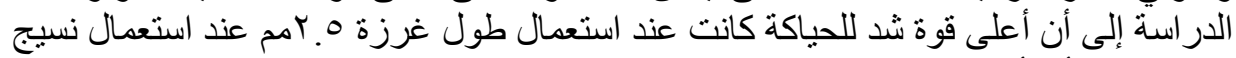

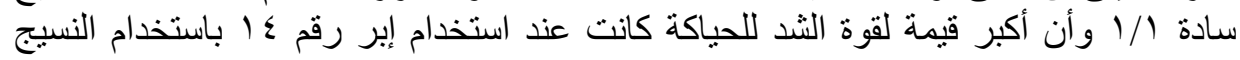

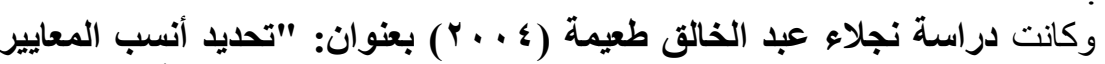

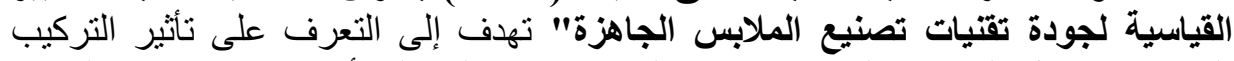

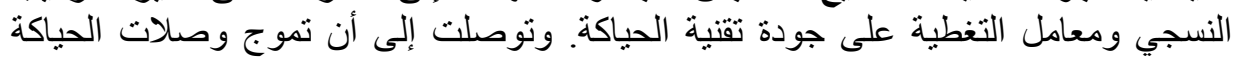

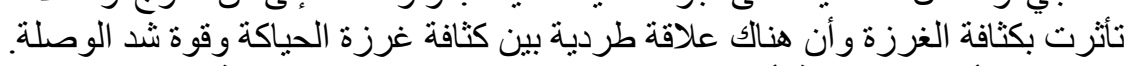

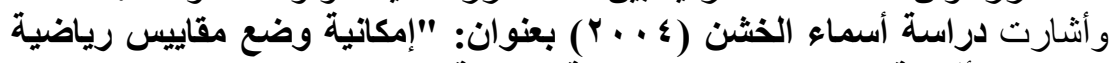

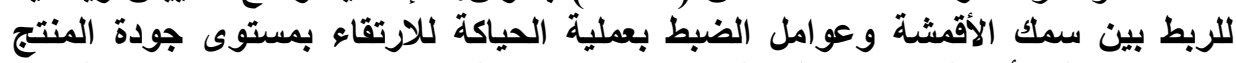

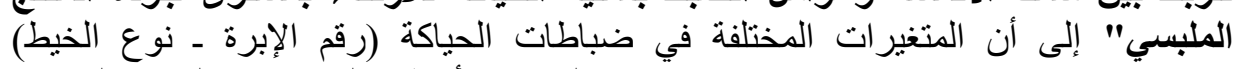
واستخراج علاقات رياضية في صورة معادلات لتفادي الأخطاء الناتجة من التقدير الإبرة التقريبي 


\section{مجلة الاقتصاد المنزلى- مجلد بr - العدد (r) - 19 ـ ب م}

لهذه الضباطات للارتقاء بمستوى جودة المنتج الملبسي، وتوصلت إلى أن هنالك علاقة طردية

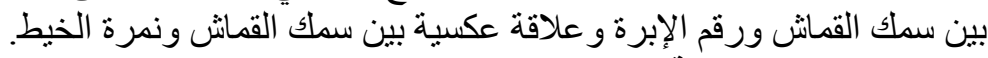

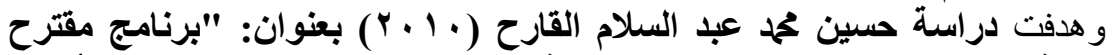

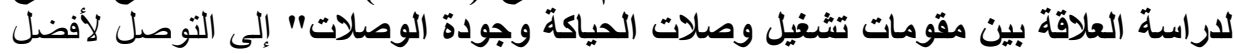

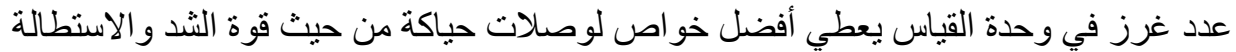

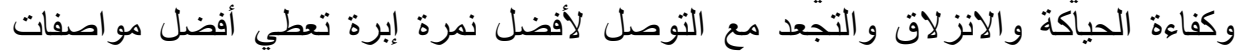

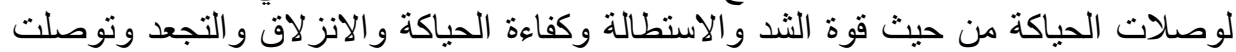

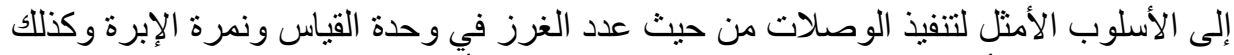

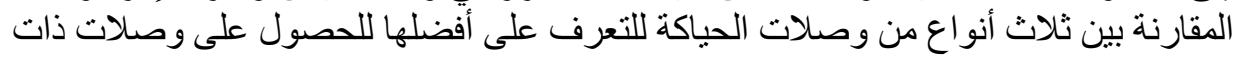

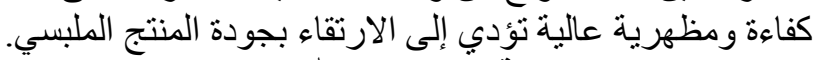

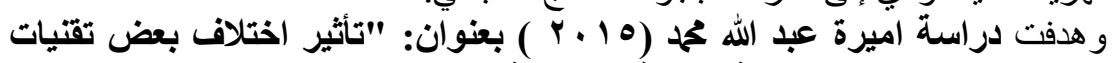

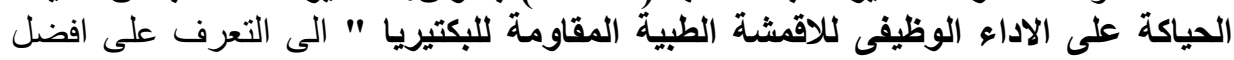

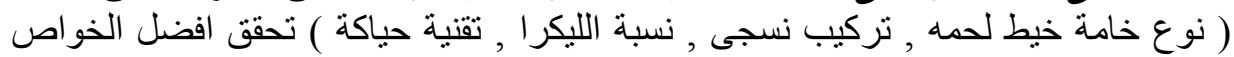

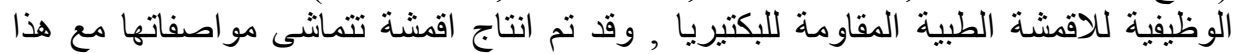

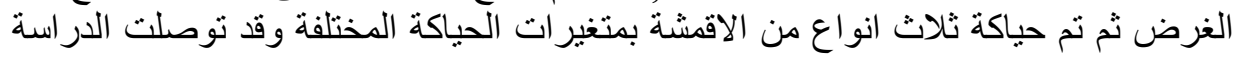

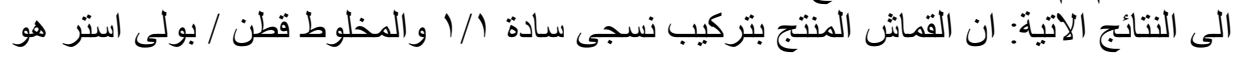

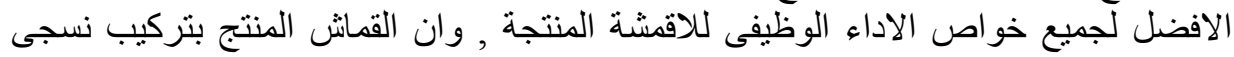

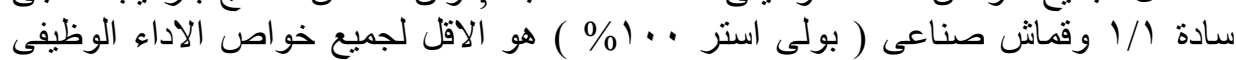

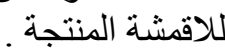
الإطار النظري: النظمئ

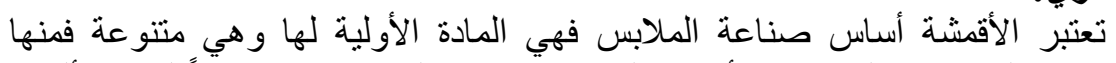

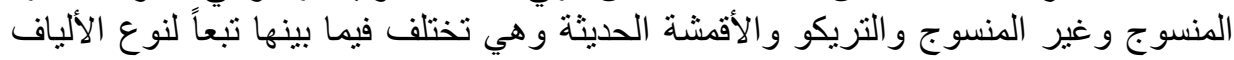

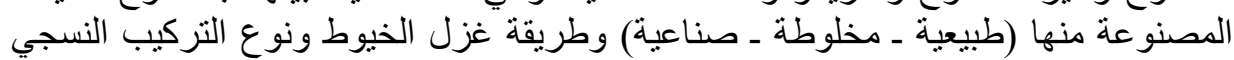

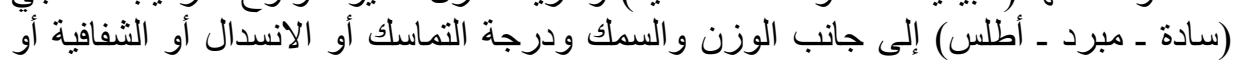

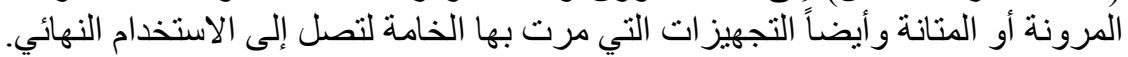

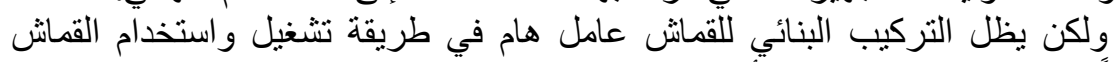

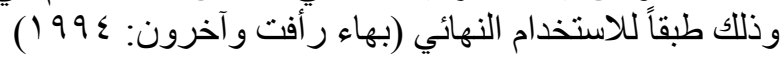

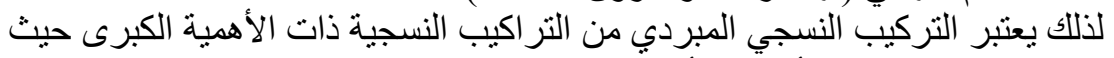

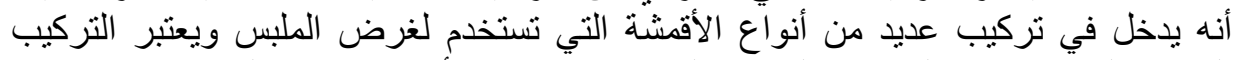

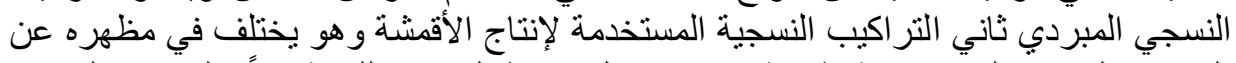

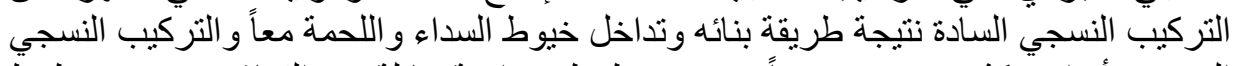

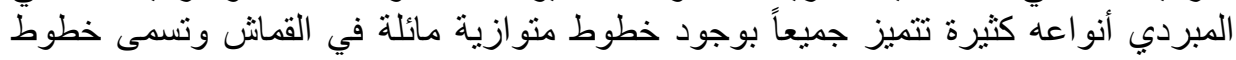

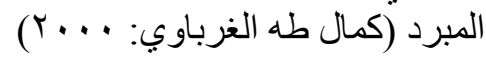

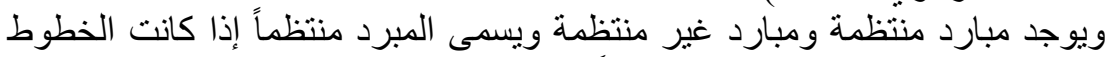

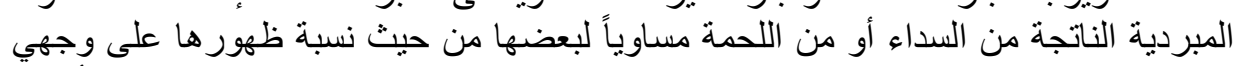

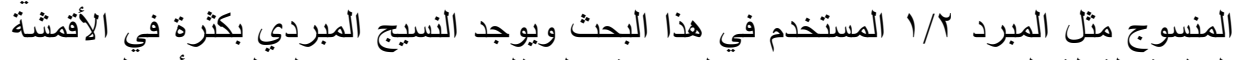

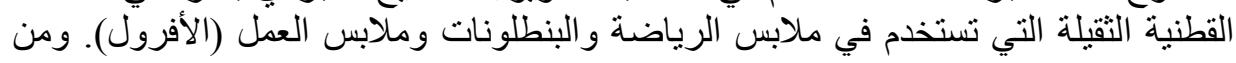




\section{مجلة الاقتصاد المنزلى- مجلد بr - العدد (r) - 19 ـ ب م}

مزايا النسيج المبردي أنه يجعل القماش منماسكاً متيناً وأنه لا يتسخ بسهولة و إذا اتسخ فإنه يحتاج لجهد في تنظيفه.

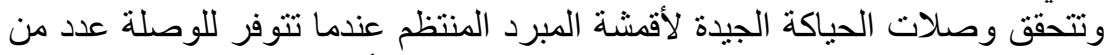

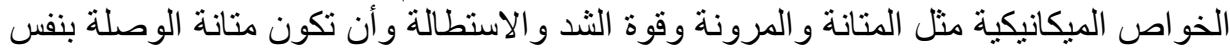

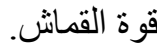

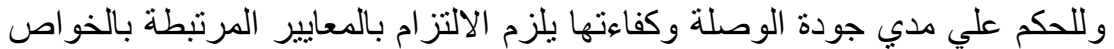

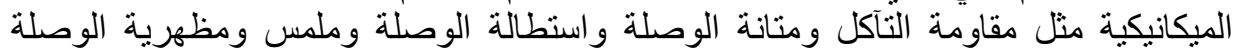

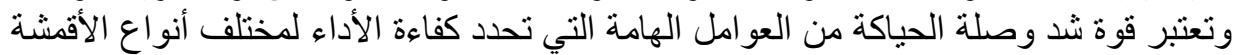

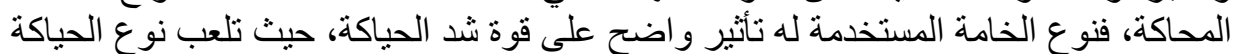

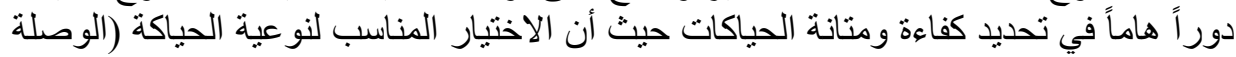

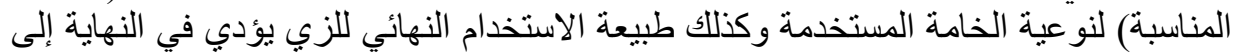

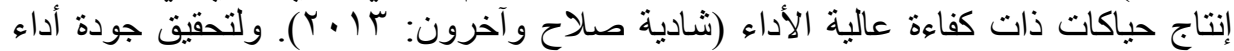

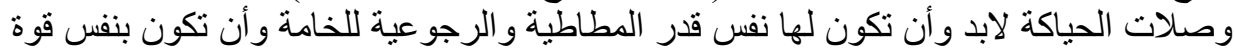

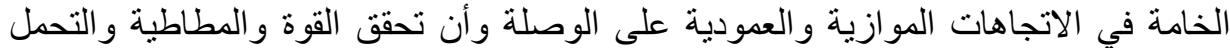

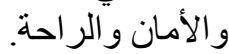

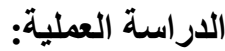

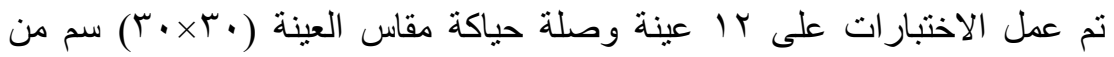
أقششة الجبردين باستخدام الثو ابت التالية:

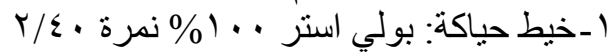
r- إبرة الماكينة: إبرة مبرومة البرة رقم 17

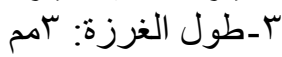

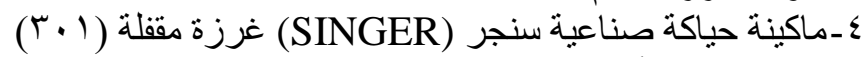
هـماكينة خياطة أوفرلوك بـ فئلة

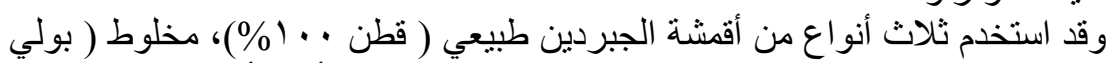

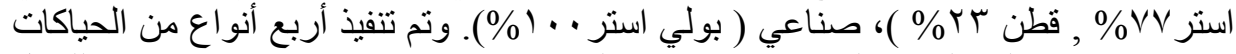

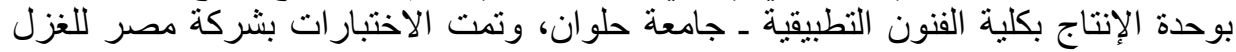

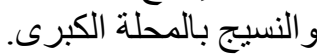
أنواع الحياكات المستخدمة في الوصلة الوصلات:

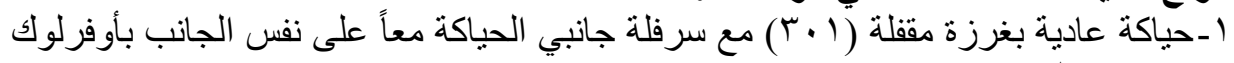

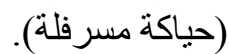
r-حياكة فرنسية ينم فيها حياكة طبقتين أحدهما على جانب والثة والثانية على الجانب الآخر

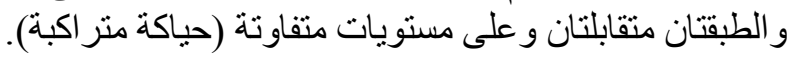

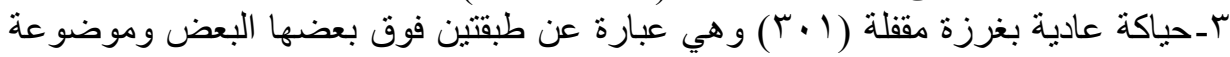

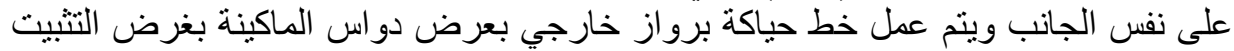

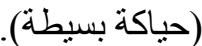
ك-حياكة عادية بغرزة مقفلة (1) (ب) مع تسطيح (تفتيح) الجانبين بالمكواة وعمل سرفلة لهم بأوفرلوك (حياكة مسطحة). 


$$
\text { مجلة الاقتصاد المنزلى- مجلد بr - العدد (r) - } 17 \text { • ب م }
$$

تم استخدام تحليل التباين الاحادى N-Way ANOVA كاسلوب احصائى ,

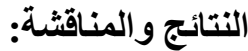
وحساب كفاءة وصلة الحياكة وفقا للعلاقة التالية :

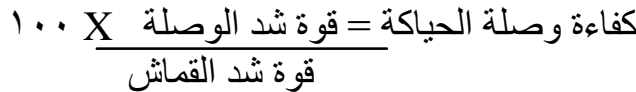
وتم دراسة متغيرات الحياكة على خو اص الحياكات مثل قوة الثند، الاستطالة، كفاءة

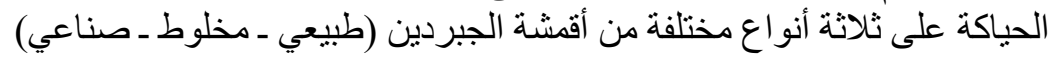

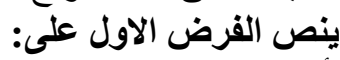

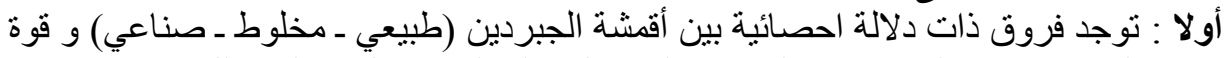

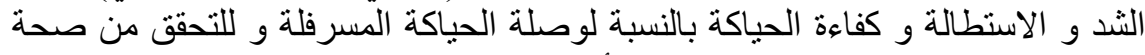

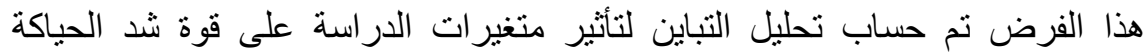

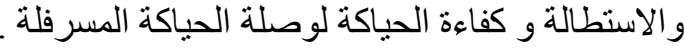

جلول (1) تحليل التباين الأحادي N-Way ANOVA لتأثير أقمشة الجبردين (طبيعي مخلوط ـ صناعي) على قوة شد الحياكه لوصلة الحياكة المسرفلة لإنة

\begin{tabular}{|c|c|c|c|c|c|}
\hline مستوى الدلالة & قيمة (ف) & الحرية & المربعات & المربعات & قوة شد الحياكة \\
\hline \multirow[t]{3}{*}{$* *$} & $Y Y . \leqslant \wedge 1$ & 11 & $117.8 \vee 9$ & rIr.r. & بين المجموعات \\
\hline & & $r \leqslant$ & $1 . r \cdot 1$ & $1 \wedge r .1 \leq 7$ & داخل المجموعات \\
\hline & & ro & & $\varepsilon q 0 . M \circ Y$ & المجموع \\
\hline
\end{tabular}

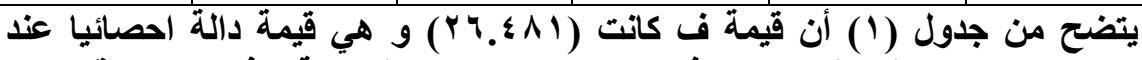
مستوى (1 .. ) مما يدل على وجود فروق بين "متغيرات الاراسة" في اختبار قوة شدة

جدول (ץ) تحليل التباين لتأثير أقمشة الجبردين (طبيعي ـ مخلوط ـ صناعي) على استطالة الحياكة لوصلة الحياكة المسرفئة المئة

\begin{tabular}{|c|c|c|c|c|c|}
\hline الدلائة & قيمة (ف) & الحرية & متوبعات & المربعوع & الاستطالة \\
\hline \multirow[t]{3}{*}{$* *$} & YY.\&VT & 11 & $11 \% .0 \mathrm{~V}$ & $\varepsilon q . . Y \wedge V$ & بين المجموعات \\
\hline & & $r \leq$ & $\varepsilon .77 \mathrm{~V}$ & TA.YAY & داخل المجموعات \\
\hline & & ro & & 001.079 & المجموع \\
\hline
\end{tabular}

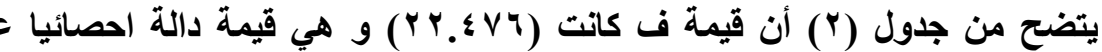
مستوى (1 +.•) مما يدل على وجود فروق بين "متغيرات الداسة" في في اختبار استطالة 


$$
\text { مجلة الاقتصاد المنزلى- مجلد צr - العدد (r) - } 17 \text { ـ ب م }
$$

جدول (r) تحليل التباين لتأثير أقمشة الجبردين (طبيعي ـ مخلوط ـ صناعي) على كفاءة الحياكة لوصلة الحياكة المسرفئلة

\begin{tabular}{|c|c|c|c|c|c|}
\hline الدلاكة & قيمة (ف) & الحرية & المربعات & المربعات & كفاءة الحياكة \\
\hline \multirow[t]{3}{*}{$* *$} & YY.\{AI & 11 & $I V . \wedge \wedge T$ & $\varepsilon 07 . Y 17$ & بين المجموعات \\
\hline & & $r \leqslant$ & 11.517 & $r \wedge . \leqslant r q$ & داخل المجموعات \\
\hline & & ro & & $\leqslant \wedge \leqslant . \vee \diamond 0$ & المجموع \\
\hline
\end{tabular}

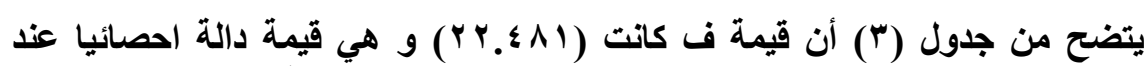

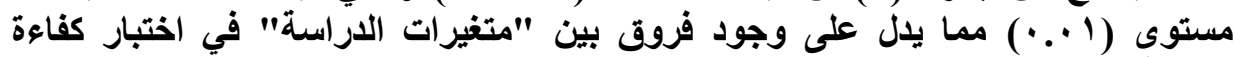

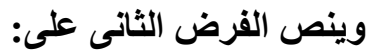

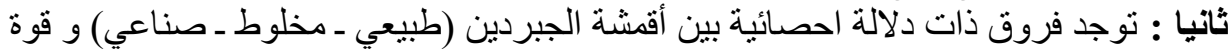

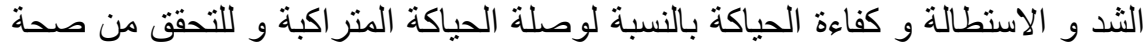

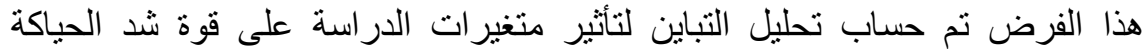
و الاستطالة و كفاءة الحياكة لوصلة الحياكة المنر اكبة .

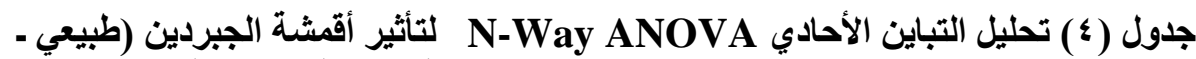

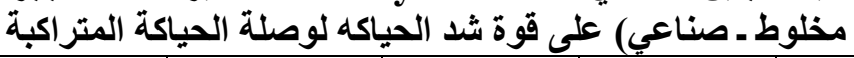

\begin{tabular}{|c|c|c|c|c|c|}
\hline مستوى الالالة & قيمة (ف) & لدرجات & المربعات & المربعات & قوة شد الحياكة \\
\hline \multirow[t]{3}{*}{$* *$} & $r \wedge . r \wedge q$ & 11 & $r \cdot \Lambda .7 \leqslant 0$ & $\varepsilon Y \varepsilon . Y \cdot V$ & بين المجموعات \\
\hline & & $Y \leq$ & $1 Y .570$ & $Y \wedge I . Y \leq 0$ & داخل المجموعات \\
\hline & & ro & & $V \cdot 0 . \leqslant 0 Y$ & المجموع \\
\hline
\end{tabular}

جدول (•) تحليل التباين لتأثير أقمشة الجبردين (طبيعي ـ مخلوط ـ صناعي) على استطالة الحياكة لوصلة الحياكة المثتر اكبة الجية

\begin{tabular}{|c|c|c|c|c|c|}
\hline مستوى & قيمة (ف) & الحرية & المربعات & المربعات & الاستطالة \\
\hline \multirow[t]{3}{*}{$* *$} & Y. TOY & 11 & YI 1.790 & $\varepsilon \wedge 1.9 \wedge \vee$ & بين المجموعات \\
\hline & & $r \varepsilon$ & $\Lambda . \varepsilon \cdot V$ & $0.7 . \leqslant 09$ & داخل المجموعات \\
\hline & & ro & & $9 \wedge \wedge . \leqslant \varepsilon \neg$ & المجموع \\
\hline
\end{tabular}




$$
\text { مجلة الاقتصاد المنزلى- مجلد צr - العدد (r) - } 17 \text { ـ ب م }
$$

جدول (†) تحليل التباين لتأثير أقشة الجبردين (طبيعي ـ مخلوط ـ صناعي) على كفاءة الحياكة لوصلة الحياكة المتر اكبة الجية

\begin{tabular}{|c|c|c|c|c|c|}
\hline مستوى الدلاية & قيمة (ف) & الحرية & المربعات & المربعات & كفاءة الحياكة \\
\hline \multirow[t]{3}{*}{$* *$} & rq.V. \& & 11 & $Y 乏 . T \wedge T$ & \& IV.MIV & بين المجموعات \\
\hline & & $r \varepsilon$ & IY.TIV & Y9.09V & داخل المجموعات \\
\hline & & ro & & $\varepsilon 97 . \wedge \wedge \varepsilon$ & المجموع \\
\hline
\end{tabular}

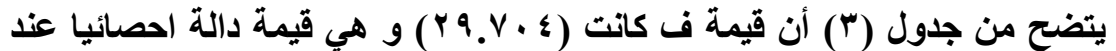

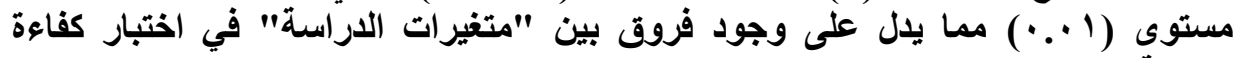

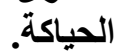

$$
\text { وينص القرض الثالث على : الثلى }
$$

ثالثا: توجد فروق ذات دلالة احصائية بين أقمشة الجبردين (طبيعي ـ مخلوط ـ صناعي) و قوة

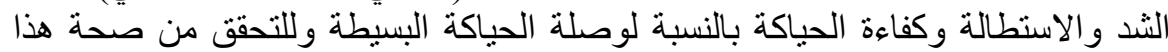

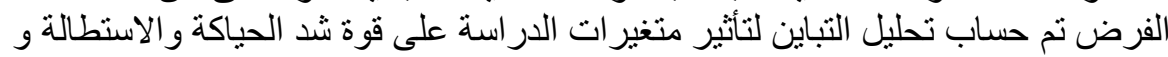
كفاءة الحياكة لوصلة الحياكة البسيطه .

\begin{tabular}{|c|c|c|c|c|c|}
\hline مستوى الدلاية & قيمة (ف) & الحرية & المربعات & المربعوع & قوة شد الحياكة \\
\hline \multirow[t]{3}{*}{$* *$} & rT.\$1A & 11 & 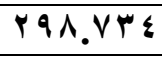 & 091.417 & بين المجموعات \\
\hline & & Y $\varepsilon$ & $1 \varepsilon .710$ & MIE.YYV & داخل المجموعات \\
\hline & & ro & & $q 1 Y .0 \leqslant r$ & المجموع \\
\hline
\end{tabular}

جدول (V) تحليل التباين الأحادى N-Way ANOVA لتأثير أقمشة الجبردين (طبيعي -

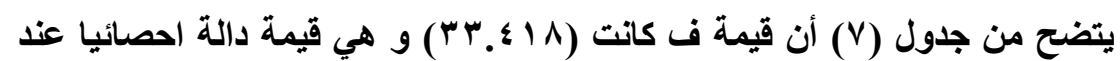

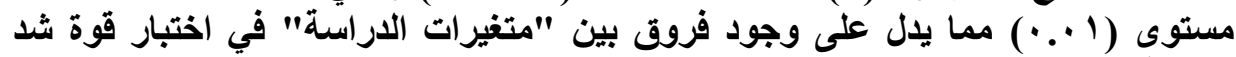

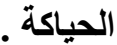

جدول (^) تحليل التباين لتأثير أقمشة الجبردين (طبيعي ـ مخلوط ـ صناعي) على استطالة

\begin{tabular}{|c|c|c|c|c|c|}
\hline مستوى الدلاكة & قيمة (ف) & لدرجات & المربعات & المربعات & الاستطالة \\
\hline \multirow[t]{3}{*}{$* *$} & $Y 7 . \leqslant 11$ & 11 & 11.071 & $01 V . V 7 \varepsilon$ & بين المجموعات \\
\hline & & $r \varepsilon$ & $9 . \varepsilon \cdot 1$ & $\vee \wedge . \Psi \backslash 1$ & داخل المجموعات \\
\hline & & ro & & 097.00 & المجموع \\
\hline
\end{tabular}
الحياكة لوصلة الحياكة البسيطة

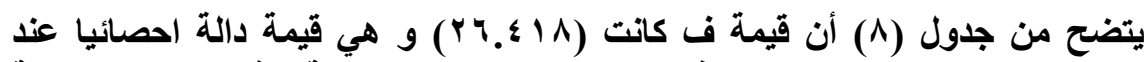

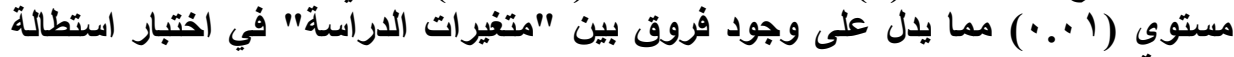




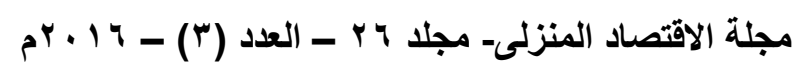

جدول (9) تحليل التباين لتأثير أقمشة الجبردين (طبيعي ـ مخلوط ـ صناعي) على كفاءة

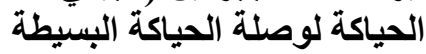

\begin{tabular}{|c|c|c|c|c|c|}
\hline مستوى الدلالة & قة قيمة & الحرية & المربعات & المربعوات & كفاعة الحياكة \\
\hline \multirow[t]{3}{*}{$* *$} & rr.TVI & 11 & $r \wedge . \vee \wedge 1$ & $01 \wedge . \leqslant Y V$ & بين المجموعات \\
\hline & & $r \varepsilon$ & IN.rIY & $r \varepsilon .011$ & داخل المجموعات \\
\hline & & ro & & OOY.qRA & المجموع \\
\hline
\end{tabular}

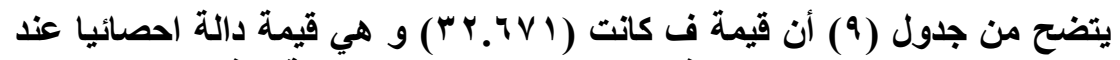

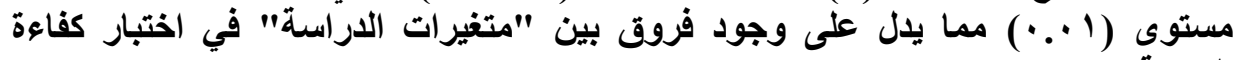

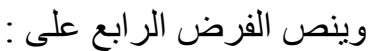

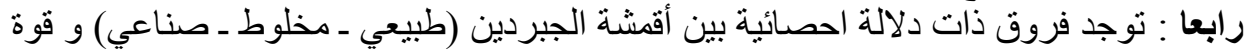

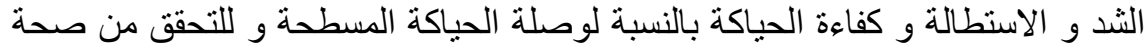

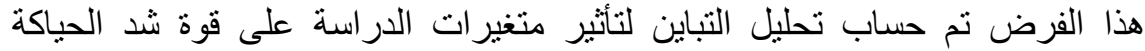

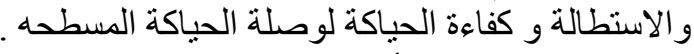

جدول (• 1) تحليل التباين الأحادي N-Way ANOVA لتأثير أقمشة الجبردين (طبيعي مخلوط ـ صناعي) على قوة شئ الحياكه لوصلة الحياكة المسطحه

\begin{tabular}{|c|c|c|c|c|c|}
\hline مستوى الدلاكة & قيمة & الحرية & المربعات & المربعات & قوة شد الحياكة \\
\hline \multirow[t]{3}{*}{$* *$} & $r 1 . r 11$ & 11 & $9 \Lambda . \& Y Y$ & $17 \varepsilon . Y . q$ & بين المجموعات \\
\hline & & $r \varepsilon$ &.$\vee \wedge 1$ & $7 \Lambda . \& 1 V$ & داخل المجموعات \\
\hline & & ro & & YYY.IYY & المجموع \\
\hline
\end{tabular}

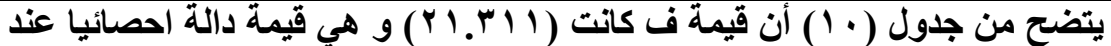
مستوى (1 .. ) مما يدل على وجود فروق بين "متغيرات الاراستة" في اختبار قوة شد الحياكة

جذول (11 ) تحليل التباين لتأثير أقشة الجبردين (طبيعي ـ مخلوط ـ صناعي) على استطالة

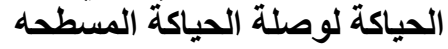

\begin{tabular}{|c|c|c|c|c|c|}
\hline مستوي & قيمة (ف) & الحرية & المربعات & المربعوع & الاستطالة \\
\hline \multirow[t]{3}{*}{$* *$} & $|\Lambda . r \leqslant|$ & 11 & $91 . .7 \mathrm{~V}$ & roy.r।I & بين المجموعات \\
\hline & & $r \varepsilon$ & r.TVV & $0 \wedge .1 \leqslant 1$ & داخل المجموعات \\
\hline & & ro & & $\varepsilon 1 \leqslant . \mu \circ Y$ & المجموع \\
\hline
\end{tabular}

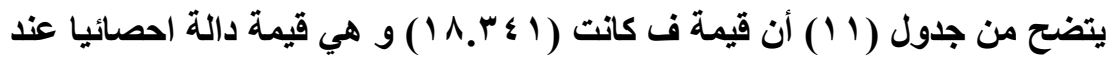

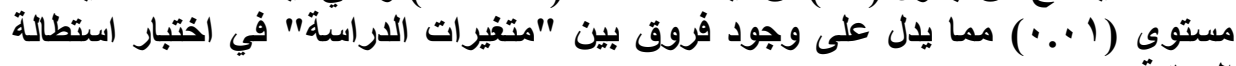

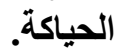




$$
\text { مجلة الاقتصاد المنزلى- مجلد צr - العدد (r) - } 17 \text { ـ ب م }
$$

جدول (r I ) تحليل التباين لتأثير أقشة الجبردين (طبيعي ـ مخلوط ـ صناعي) على كفاءة الحياكة لوصلة الحياكة المسرفئة

\begin{tabular}{|c|c|c|c|c|c|}
\hline مستوى الدلالة & قيمة (ف) & الحرية & المربعات & مجموع المربعات & كفاءة الحياكة \\
\hline \multirow[t]{3}{*}{$* *$} & 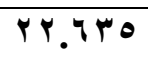 & 11 & $10 . \wedge \mathrm{VI}$ & MI & بين المجموعات \\
\hline & & $r \leqslant$ & 9.411 & $r r .0 \leqslant q$ & داخل المجموعات \\
\hline & & ro & & Pr.97. & المجموع \\
\hline
\end{tabular}

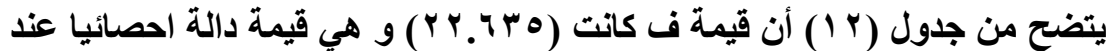

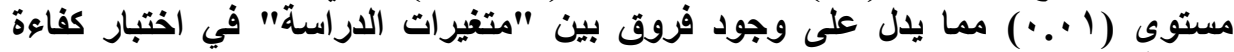

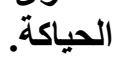

ومن النتائج السابقه يتضح ان افضل نوع وصله حياكه هى الحياكه البسيطه مع الجبردين

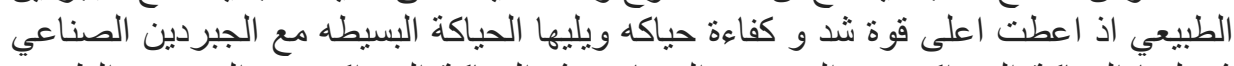

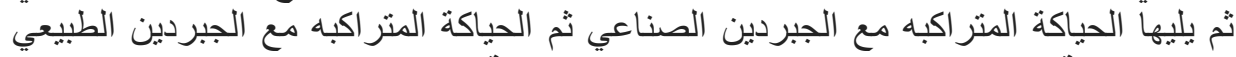

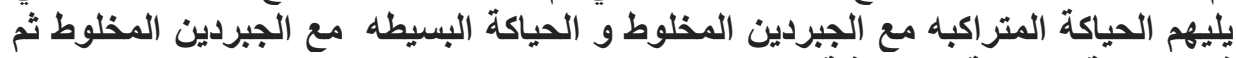

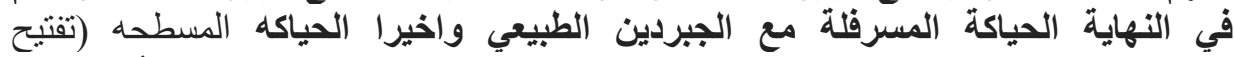

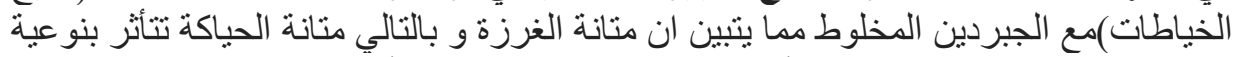

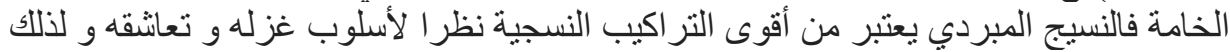
فهو يعطي نتائج عالية الاداء.

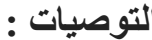

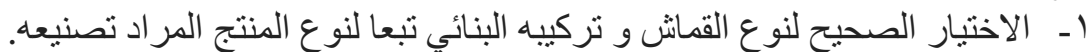

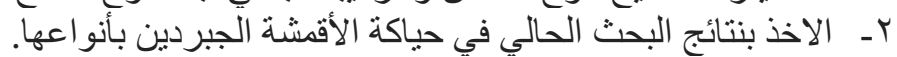

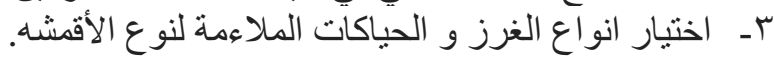




\section{مجلة الاقتصاد المنزلى- مجلد بr - العدد (r) - 19 ـ ب م}

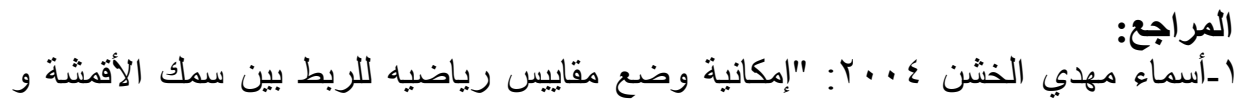

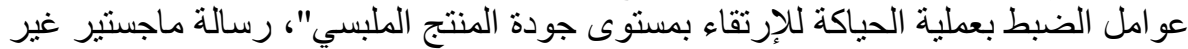

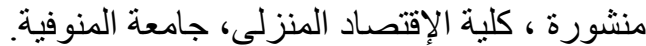

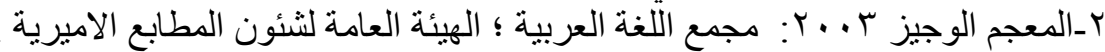

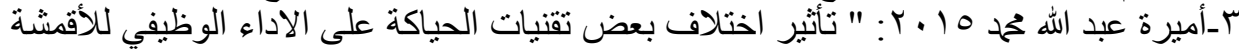

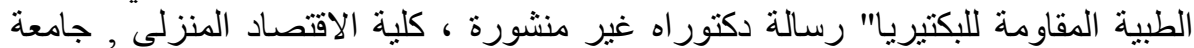

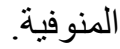

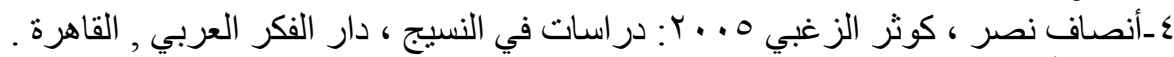

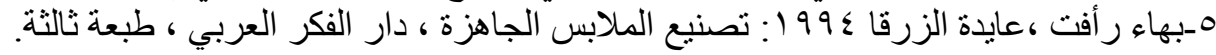

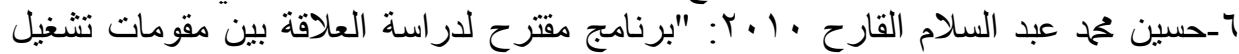

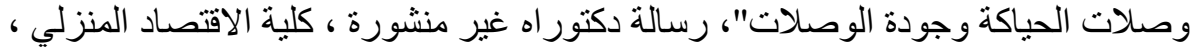

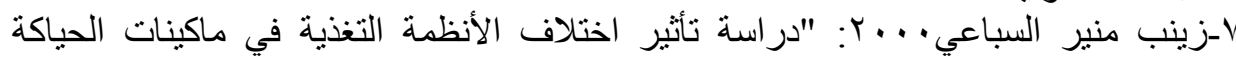

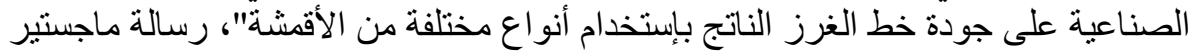

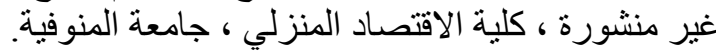

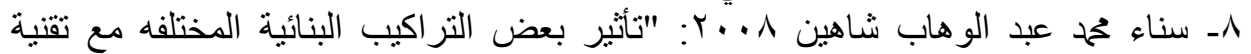

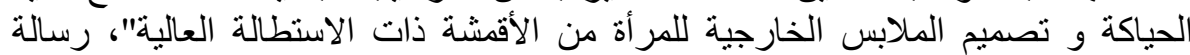

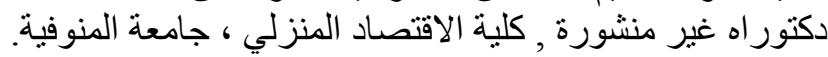

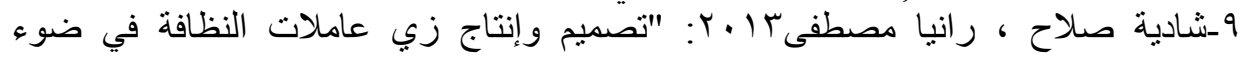

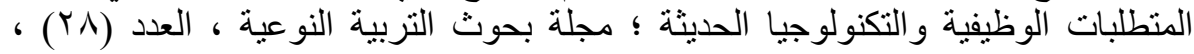

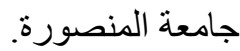

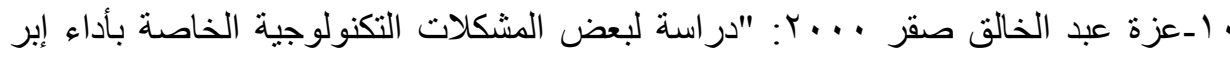

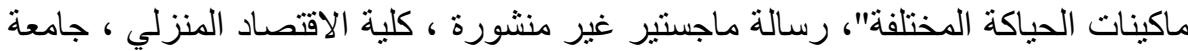

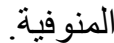

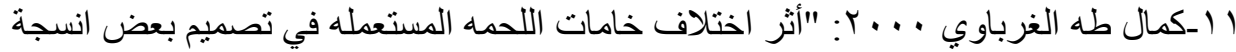

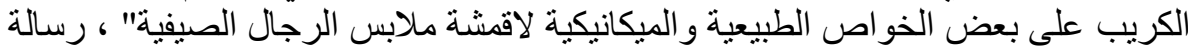

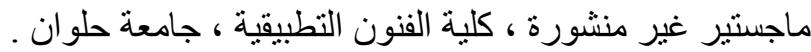

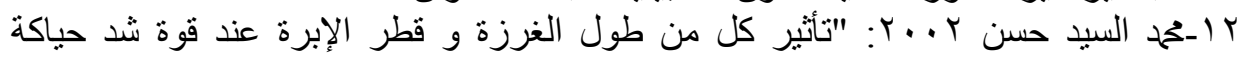

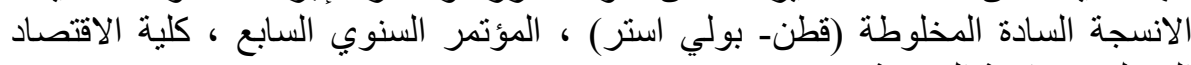

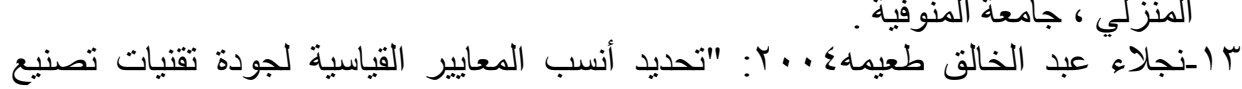

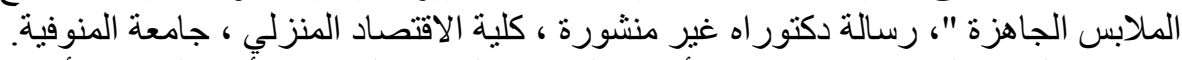

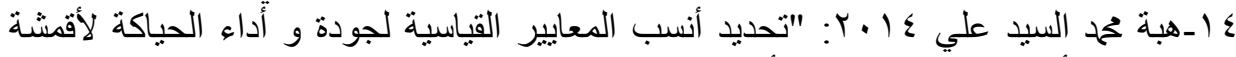
ملابس الأطفال القطنية المنفذة بأسلوب البيكة"، رسالة ماجستير غير منشورة , كلية التربية

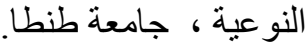




$$
\text { مجلة الاقتصاد المنزلى- مجلد צr - العدد (r) - } 17 \text { • ب م }
$$

\title{
Studying the Effect of Different Kinds of Twill ( Gabardine) Fabrics on Some Mechanical Properties of Sewing Joints
}

\author{
By: Enas El Sayed El Doridy \\ Faculty of Specific Education - Benha University
}

\begin{abstract}
:
Twill Fabric is considered as the second textile which is commonly used and it differs in its appearance from the plain fabric as a result of its construction method and the entrance of wrap and weft thread together and fabric composition Twill, it has many kinds all are characterized by parallel lines in the fabric with its appearance in the direction of the warp and the weft and it is called the Twill lines so this research deals with the effect of four types of sewing on different kinds on the gabardine (natural- bland - synthetic) and study the effect mechanical properties like tightening force and extended and durability on the quality of the sewing joints, the research reached in its results that the best type of sewing is the simple sewing with the natural gabardine then the simple sewing with the synthetic gabardine (polyester100\%) then the decorated sewing with the natural gabardine (100\% cotton) then the flatted sewing with the bland gabardine (polyester 77\% - cotton $23 \%)$.
\end{abstract}




$$
\text { مجلة الاقتصاد المنزلى- مجلد بr - العدد (r) - } 17 \text { ـ ب م }
$$

ملحق (1)

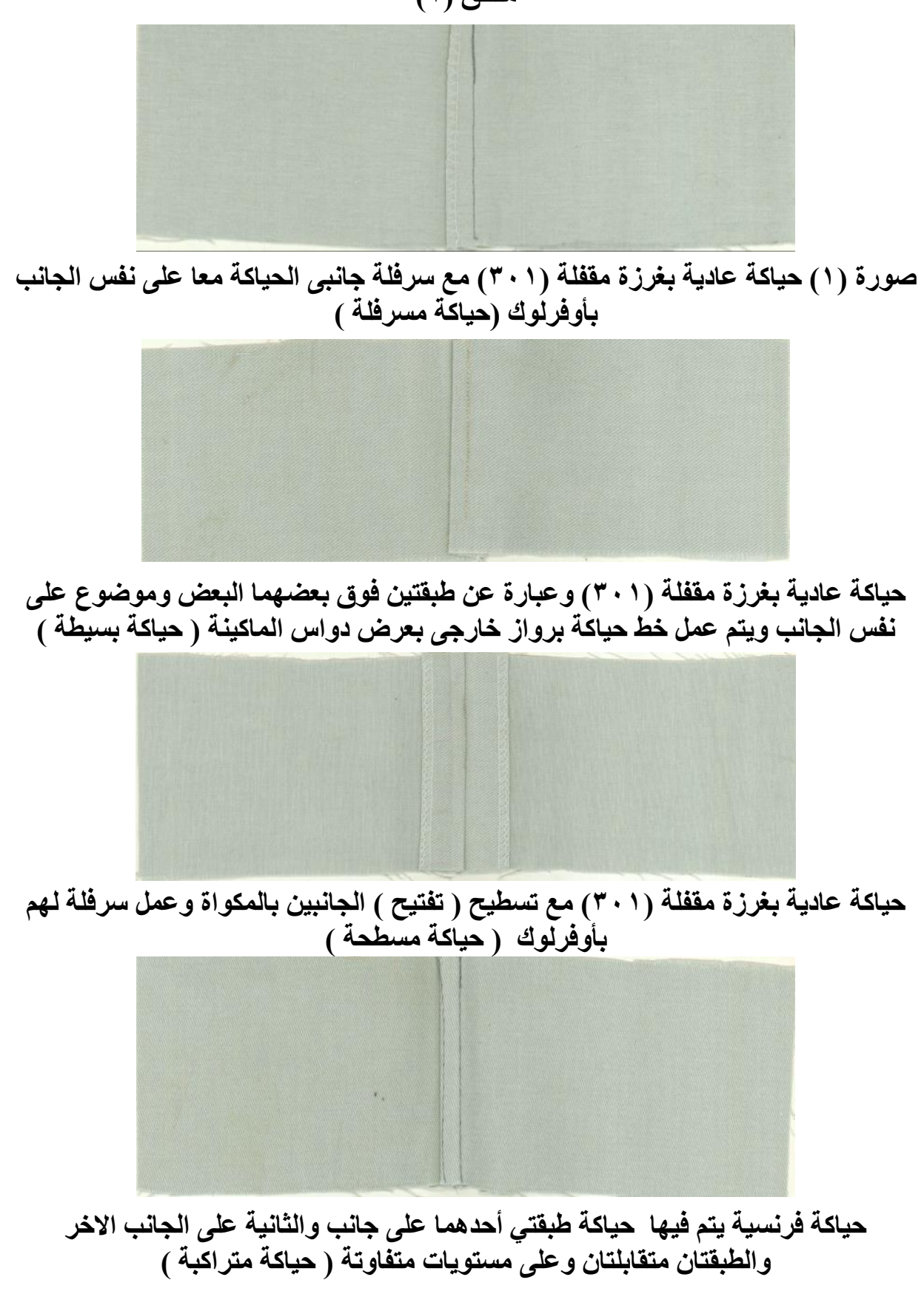

